\title{
ORACLE METHODOLOGIES FOR MANAGING BUSINESS SOLUTION PROJECTS
}

\author{
Alaeldeen Wild Ali \\ Faculty of Organizational Sciences, University of Belgrade, Serbia
}

\begin{abstract}
IT projects are quite complex for managers unfamiliar with IT industry trends and technological advancements. The complexity of these projects makes it difficult for conventional managers to deploy IT projects without proper awareness of the technical insights. This is the primary reason that some methodologies for IT management projects have become popular in the industrial world. The objective of these methodologies is to provide a template for implementation of an IT project in a business scenario. Different methodologies have their core advantages and limitations, and so it is important to identify the most suitable methodology based on project type, scope, location and industry. In this paper, an assessment is presented that critically evaluates the reasons for, and implications of, adopting the Oracle Aim for Business Flow (ABF) methodology in the Special Economic Zone (SEZ) of Aqaba, Jordan, for the Aqaba Community and Economic Development (ACED) program. Success of the ACED program presents evidence that the $\mathrm{ABF}$ is versatile in diverse scenarios and can dynamically adapt to both changing business environments and the requirements of the clients.
\end{abstract}

Key words: ACED, ASEZA, US-AID, Oracle ABF.

\section{INTRODUCTION}

Business operations are a highly complex process that become more complexity with growth in the scale of operations. This is the factor of business operations that has inspired the development of business purpose management tools such as Enterprise Resource Planning (ERP) systems and EPM (Enterprise Performance Management) systems. These systems are implemented on enterprise levels for optimal management of an organization's operations. Some of the biggest corporate solutions available in business management include: Oracle applications, Microsoft Dynamics, SAP ERP systems, and Odoo (Narayanamurthy \& Gurumurthy, 2017).

In large scale business operation scenarios, the implementation of different business solution applications such as, resource planning, performance management, and quality assurance, may appear obvious, but they can sometimes lead to a mismatch in business direction because there is a lack of a comprehensive approach and strategy in use of all applications in a collective manner. For instance, if the ERP system is directed to manage a process with the objective of keeping the cost the lowest, it impacts the business direction of offering the highest quality products in the industry, which then requires resources to enhance the product quality (Aureli, Ciambotti, Jóczik, \& Sasvari, 2015). Accordingly, there would not be a match of operational flow for business objectives among the business solution applications. To achieve a harmony among different business solution applications adopted for a business operations task, it is important to adhere to a methodology that directs all business aspects and operations towards a single objective.

Oracle is one of the biggest global organizations that offers popular business management and project management applications to corporations in the form of proprietary business applications such as: financial (FIN), supply chain management (SCM), customer relationship management (CRM), and human capital management (HCM) (Cokins, 2017). As many large corporations adopt more than one Oracle business application for different domains of their organizational management. It is important that all business applications remain aligned with one another and work towards the same business direction and goals. For this 
purpose, Oracle has developed its AIM (application implementation methodology), which is a methodology for implementing its business purpose applications like ERP, EPM and CRM systems. An extension to this methodology was introduced by Oracle in the form of AIM for Business Flow (ABF), a methodology that foresees implementation of Oracle applications in different business domains (James, Russell, \& Seibert, 2003). Development of this methodology has been performed by Oracle organization on the basis of a long continuous collaborative partnership with connected businesses.

In this paper, the benefits and contributions of AIM for the business flow (ABF) methodology of Oracle are examined for the Aqaba community and economic development (ACED) project. The project was overseen by US-AID (United States Agency for International Development) and Aqaba Special Economic Zone authority (ASEZA). This project made use of many different Oracle business solutions throughout the lifecycle of the project and, accordingly, managers adopted the Oracle $\mathrm{ABF}$ methodology for proper alignment of business operations in the implementation phase. The aim of this study is to analyse the case study of the ACED program to evaluate the contributions of the $\mathrm{ABF}$ methodology to this project and the benefits that adopting this methodology have provided to the project.

\section{BACKGROUND TO ORACLE AIM METHODOLOGY}

The AIM methodology of Oracle is a welldefined approach that provides a guideline for implementing various Oracle applications for business use across all aspects of a business with proper alignment. Developed in collaboration with Oracle partner businesses, the AIM methodology is rooted in the realities of business operations.

Oracle itself touts its AIM methodology as a combination of methodological tools that allows for business managers to perform planning, and to conduct and control different operations in the lifecycle of a project in an efficient and effective manner to make the project successful.
AIM tools by Oracle exist in software packages that contain comprehensive documentation to guide managers through template designs. These templates serve as deliverables of the AIM methodology and need to be adhered to by the project managers (Radhakrishnan \& Balasubramanian, 2008). By design, Oracle AIM deliverables are easy to understand and are commonly delivered in editable file formats, such as word documents, and excel spreadsheets.

The Oracle AIM methodology software package is only offered to organizations that are Oracle partners in the OPN (Oracle Partner Network). The software package is a simple tool that can be installed on any system. Its deliverables are filled by project managers.

The AIM methodology of Oracle is flexible enough to be implemented for any type of IT software deployed in a company; however, the most notable aspect of the methodology is the documentation template provided within the package. The major deliverables that are part of the Oracle AIM methodology are as follows, each containing several sub-deliverables: (Smiers, Deb, Koster, \& Palvankar, 2015)

- Business process architecture (BP)

- Business requirements definition (RD)

- Business requirements mapping (BR)

- Application and technical architecture (TA)

- Module design and build (MD)

- Data conversion (CV)

- Documentation (DO)

- Business system testing (TE)

- Performance testing (PT)

- Adoption and learning (AP) or User training

- Production migration (PM)

\section{ABF METHODOLOGY}

Oracle's AIM for business flow (ABF) methodology has its foundation in the AIM methodology and adds a requirement to define the flow of business operations and processes. As per the Oracle organization, use of the ABF methodology is mostly recommended for businesses that operate in green field style of projects, i.e. projects that do not have an existing or well-defined structure of processes or operations (Siddiqui, 2010). The 
unstructured and uncertain nature of such business projects make it difficult for such projects to adopt standard business flow approaches.

The complete methodology of Oracle ABF can be found in these five sequential stages:

- Definition phase

- Elaboration phase

- Build phase

- Transition phase

- Production phase

Across all phases of the ABF methodology of project implementation, there are several deliverables that are specific to that phase. Listed below are all the deliverables that are important to deliver to adhere to the methodology.

Table 1: Deliverables to ABF methodology (Hull, Mendling, \& Tai, 2010)

\begin{tabular}{|l|l|}
\hline $\begin{array}{l}\text { Deliverable } \\
\text { code }\end{array}$ & Deliverable(s) \\
\hline BF.015 & Future process model \\
\hline BF040 & Change catalogue \\
\hline BF100 & $\begin{array}{l}\text { Phase end review } \\
\text { documents }\end{array}$ \\
\hline BF.016 & $\begin{array}{l}\text { Application extensions } \\
\text { functional design }\end{array}$ \\
\hline MD050 & $\begin{array}{l}\text { Application extension } \\
\text { technical design }\end{array}$ \\
\hline BF045 & Functional design \\
\hline TE040 & $\begin{array}{l}\text { Sest script } \\
\text { script integration test }\end{array}$ \\
\hline TE050 & User guide \\
\hline DO070 & $\begin{array}{l}\text { Conversion } \\
\text { mapping }\end{array}$ \\
\hline CV040 & $\begin{array}{l}\text { Installation instructions } \\
\text { listing }\end{array}$ \\
\hline MD120 & $\begin{array}{l}\text { Levels of access to the } \\
\text { system }\end{array}$ \\
\hline BF080
\end{tabular}

The AIM for Business Flow (ABF) methodology of Oracle takes elements from the AIM methodology as defined by Oracle, but it makes changes to target an efficient and effective flow of business operations. The differences and contradictions between the
AIM and ABF methodologies are described in Table 2 below.

Table 2: Difference between ABF vs AIM (Porwal, 2016)

\begin{tabular}{|l|l|}
\hline Traditional A.I.M. & ABF Methodology \\
\hline $\begin{array}{l}\text { Driven by } \\
\text { requirements }\end{array}$ & $\begin{array}{l}\text { Drive by the } \\
\text { optimum solution }\end{array}$ \\
\hline $\begin{array}{l}\text { Solution gets } \\
\text { defined during the } \\
\text { project lifecycle on } \\
\text { basis } \\
\text { requirements }\end{array}$ & $\begin{array}{l}\text { Flow of the solution } \\
\text { is set prior to launch } \\
\text { of the project }\end{array}$ \\
\hline $\begin{array}{l}\text { Follows the } \\
\text { conventional } \\
\text { Waterfall model }\end{array}$ & $\begin{array}{l}\text { Makes use of an } \\
\text { iterative approach on } \\
\text { basis of CRPs }\end{array}$ \\
\hline $\begin{array}{l}\text { Customizations are } \\
\text { made whenever the } \\
\text { standard } \\
\text { functionality of the } \\
\text { application does not } \\
\text { satisfy requirements }\end{array}$ & $\begin{array}{l}\text { Makes efforts to } \\
\text { avoid customizations } \\
\text { and makes priority to } \\
\text { support changes }\end{array}$ \\
\hline $\begin{array}{l}\text { Puts the focus on } \\
\text { individual modules } \\
\text { of the system }\end{array}$ & $\begin{array}{l}\text { Puts emphasis on } \\
\text { efficient flow of } \\
\text { cross module } \\
\text { processes }\end{array}$ \\
\hline
\end{tabular}

\section{CASE STUDY - ACED PROGRAM}

The Aqaba Community and Economic Development (ACED) program was a jointventure of the Aqaba Special Economic Zone authority and US-AID (United States Agency for International Development) in Aqaba, Jordan. This program was planned as a fiveyear long project to develop an economic zone in Aqaba. It aimed to develop the area from both an economic and a community perspective by giving the citizens of Aqaba access to ample good-paying job opportunities, and education systems for skill development (Aced-jordan.com, 2015). The ACED program started in June 2007 with its planning phase, and completed in August 2012.

The Aqaba Special Economic Zone (ASEZ) was developed in 2001. Its objective was to appeal to business developments and economic growth in the area by developing a cluster of business industries. Aqaba Special Economic Zone Authority (ASEZA) was the authoritative body of government that oversaw the management of this program. In whole, the zone was given several benefits and reliefs to be developed as an industrial cluster, such as: 
duty-free industries, low taxation on industrial operations, and a long coastline for sea trades.

At the time, ASEZA requested assistance from the US-AID agency to provide technical and functional guidance as ASEZA did not have the expertise nor the capacity to efficiently plan the program and regulate the operations (Acedjordan.com, 2015). The market and industrial scenario of ASEZ was heavily dominated by small and medium enterprises (SMEs) in 2007. It was identified that these SMEs had not adopted the modern management tools and techniques, causing them to become very backward in comparison to their global competitors. Furthermore, the local population did not have enough skill development or expertise to benefit from the economic growth that the ACED project was supposed to bring to the region.

\subsection{Challenges faced}

At the time, when the ACED program was launched in 2007, the Jordanian Kingdom was facing two very fundamental challenges that restricted growth of the local economy:

(i) local SMEs and businesses had very low competitiveness compared to the global economy, and

(ii) a high rate of unemployment coupled with a low skilled in population in the Aqaba area.

With the ACED project, both ASEZA and the US-AID agency targeted significant developments for the economy of Jordan in a five-year program. However, it was identified that while the economic and industrial growth programs would provide employment opportunities to the local citizens, there was not enough ample skill or expertise among local residents. They were therefore unable to take full advantage of the economic development that was to arrive in the region. This provided another challenge; they had to overcome the lack of sufficient skills in the population by deploying education programs and targeting industrial training (Ammon News, 2010).

The ACED program was designed by US-AID (United States Agency for International Development) and ASEZA (Aqaba Special Economic Zone Authority) with the objective of ensuring that the Aqaba city industrial area was developed to provide good-paying employment opportunities to the residents, and to achieve industrial development to make local industries competent against global competition.

In deploying many applications and technological advancements, this project made use of Oracle's ABF (AIM for Business Flow) methodology to implement the new technological tools and systems in local industries. The various templates and process design structures of ABF were used by the USAID to make the managers and personnel understand how to design business processes and define best practices to follow in a competitive industry.

A major challenge in implementing the ERP system for the ACED project was related to localization of the system and its implementation strategy. ERP systems are very sophisticated in design, and for a naïve user with minimal exposure to modern business applications, making use of an ERP system while also guiding implementation of it can be very challenging. At the start of the ACED project, it was apparent that the majority of businesses in the Aqaba area were small and medium enterprises, with little to no use of modern business software tools to ease business flow and strategic decision. For this reason, use of easy-to-understand templates and best practices were sought for the ACED project.

\subsection{Goal of using ABF at ACED program}

US-AID agency and ASEZA used Oracle ABF methodology to implement an ERP system for the ACED project with the following objectives:

- User training for work on the ERP systems through the templates and best practices provided within the ABF software package (US-AID.gov, 2012).

- Improving quality of operations in the ACED project by adhering to the best practices defined by $\mathrm{ABF}$ methodology.

- Using ABF methodology to direct all business operations and resources towards optimum business flow by 
making use of most suitable ERP system and its implementation (USAID.gov, 2012).

- Effectively using each phase defined in the $\mathrm{ABF}$ methodology to implement the ERP system for ACED project that achieves the most efficient outcomes.

\section{IMPLEMENTATION OF ORACLE ABF AT ACED}

In its basic design, the Oracle ABF methodology is designed to serve as an implementation approach for business applications and software tools in a project for the most efficient and effective outcomes. The methodology makes use of the Oracle AIM (application implementation methodology) for business flow. In accordance with this methodology, all the different tasks that are part of a project get categorized and organized as smaller processes. For each organized process, there is a fixed set of goals, requirements for resources, and defined outputs in the form of deliverables (Abel, 2006). Each task has the maximum capacity of belonging to a single process. Using this methodology, project managers are required to assign human resources to individual processes on basis of their skills and area of expertise.

For the case of the ACED project, the ABF methodology was used for all five phases as shown in Figure 1 below.

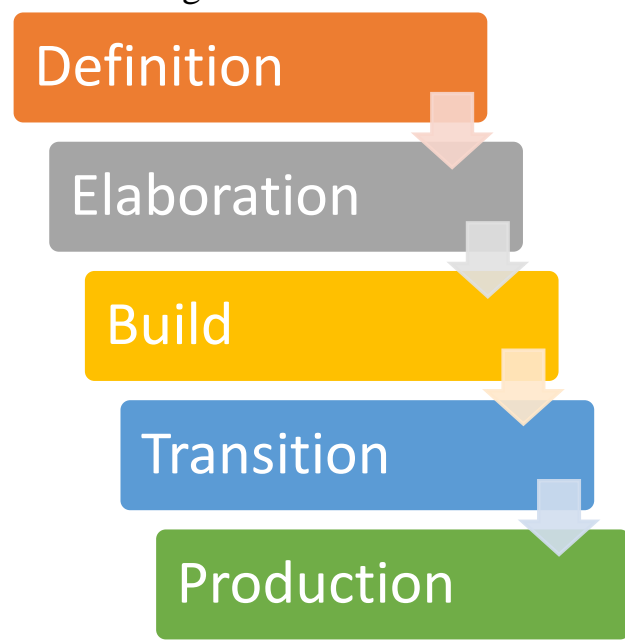

Figure 1: Phases in ABF methodology (LeviJakšić, 2012)

Processes defined by the ABF methodology for the ACED process included the following: i. Business process mapping

ii. Application and tech architecture

iii. Module design and build

iv. Data conversion

v. Documentation

vi. Business system testing

vii. Performance testing

viii. Adoption \& learning

ix. Production migration

For the ACED program, the need for an ERP system was apparent in the unorganized flow of business operations and processes. For this purpose, the Oracle ABF approach was used to implement the ERP system in the ACED project. Various assets of the ABF methodology were used to align the business aspects of the ACED program. In this approach, project managers used the templates, best practice guidelines, and business flows as defined in the $\mathrm{ABF}$ methodology to map the requirements and business decisions of the program (Aced-jordan.com, 2014).

One of the biggest advantages offered by the $\mathrm{ABF}$ methodology in the ACED program was to save time without compromising the quality of the outputs in any way. For example, by adopting the $\mathrm{ABF}$ methodology, ACED project managers had readily access to the best practice guidelines as defined by the $\mathrm{ABF}$ methodology. These guidelines are derived from the worldwide collaboration of the business application implementation along with elements of localization aspects, such as regulatory framework and legislative considerations (Aced-jordan.com, 2014). This aspect of the $\mathrm{ABF}$ methodology avoided the requirement to spend time gathering system requirements for the ERP system by analysing the structure of current business processes. This advantage offered by using Oracle's ABF methodology enabled the program to save a lot of time and to begin the operational phases of the ERP system project very quickly.

\subsection{Suitability of ABF for ACED?}

At the launch of the ACED project, local businesses were not very competitive, and the region of Jordan was not familiar with advanced business applications to support business decisions and introduce efficiency to the project. In this scenario, local professionals in the region were not familiar with the 
business applications like advanced ERP systems and its components. Furthermore, SMEs that dominated the Jordanian markets did not make use of sophisticated systems for business applications. There was low localization and a lack of readily available knowledge of business applications for the market. In this scenario, the majority of the business application products available in the market did not satisfy the requirements of ACED, specifically due to a lack of localization and a high dependence on skilled personnel (Anandi, 2009).

As $\mathrm{ABF}$ put more focus on understanding the requirements of the ACED project through the standard business flows of Oracle, it was more suitable to satisfy the requirements of the ACED program by the proper mapping of processes. In contradiction with the conventional AIM methodology that employs predefined operational processes using the waterfall model, the $\mathrm{ABF}$ approach was changed to make use of numerous CRPs (conference room pilots) to make the end-users and managers in the ASEZ region more familiar with the Oracle ERP system (Noor Al Hussein Foundation, 2009). Using this methodology, managers and professionals working in the local industries were given detailed presentations and a hands-on teaching approach of the ERP system, a practice that is not common with other methodologies.

\subsection{Success of the ACED program through ABF methodology}

The collective efforts made by both ASEZA and US-Aid in the careful planning and implementation of the ACED program through the use of the ABF methodology was deemed successful upon conclusion, establishing a thriving industry and prosperous community in the city. Some of the critical successes of the program include the following:

- Following on the concepts of ABF methodology, ASEZA was able to set a clear vision for the ACED project from the very beginning, as the ABF methodology puts emphasis on clear long-term objectives in the 'definition phase' of ABF (Aced-jordan.com, 2014).
- Use of ABF methodology in the implementation of the ERP system in the ACED program assisted the local industrial area by training users to have a pool of managers that were able to make use of ERP systems in an effective manner.

- Upon implementation of the ERP systems in the ACED project, the industrial operations in ASEZ moved towards the use of business applications like the ERP system for higher productivity, optimized business processes, and targeted flow of business for business objectives.

- Use of the ERP system implemented by the ABF methodology in the ACED program was more requirement oriented of the Aqaba area. This aspect of the methodology ensured that the eventual ERP system implemented in its final form was the most suitable ERP system that satisfied all the requirements of the project from an ERP system, identified in the definition phase of ABF methodology (US-AID.gov, 2012).

- In selection and implementation of an ERP system and methodology adopted for implementation purposes, it is important that the methodology is localized to consider factors based on local economy, culture, and conventional business practices (USAID.gov, 2012). As the ABF methodology is developed by Oracle from its truly worldwide network of collaborative partners, the Oracle ABF methodology software package was well-localized to accurately and reliably identify requirements of ASEZ that were addressed by ACED project.

- For the SMEs dominated business industries of Aqaba that were virtually untouched by modern business applications, successful use of the ABF methodology for the implementation of an ERP system presented the much-needed exposure to business applications along with the ease of careful implementation. As a result of this, more SMEs and entrepreneurs in the region started to implement ERP systems, CRM 
systems and EPM systems to make business processes more productive and effective (Noor Al Hussein Foundation, 2009).

\section{CONCLUSION}

Innovation and advancements in business technologies have gained popularity in recent decades. Businesses of all scales now make use of advanced technologies to operate more efficiently. The Implementation of business applications like ERP systems, EPM systems and CRM tools, is becoming a common trend across SMEs and large-scale enterprises. These systems require a lot of financial and human resource investment for a project, and accordingly, success from the implementation project is also very critical. Therefore, it is vital that prior to the implementation of a business application, requirements are well-identified to ensure that all requirements are met with the selected application. In addition to this, the methodology of implementation is also very crucial for the success of a project, as it leads to proper alignment with other factors in the industry.

This paper presents a careful examination of the reasons for, and approach to, the deployment of Oracle's AIM for Business Flow (ABF) methodology for the ACED (Aqaba Community and Economic Development) program in Jordan for the implementation of an ERP system. The program was a success in the region and established ASEZ (Aqaba Special Economic Zone) as a major economic strength by introducing tools of economic growth and skill development for the community. The industrial area of ASEZ experienced significant growth and achieved its goals of attracting inward investment from outside investors. Analysis of the Aqaba case study reveals the extent to which the Oracle ABF methodology is suitable to use in the implementation of an ERP system for the ACED project along with its implications on that project. By adopting the ABF methodology, it is clear that the implementation of an ERP system for the ACED program became more straightforward and convenient with providing access to the best practices in ERP system implementation, along with predefined templates for implementation process found in the $\mathrm{ABF}$ software package.

Selecting the ABF methodology has proven highly beneficial for the ACED program due to its inclination towards understanding the requirements of the client and using the best practices of implementing an ERP system to satisfy those requirements. In the success of the ACED project and the subsequent ACED II project, the contributions of adopting the Oracle ABF methodology have been significant.

\section{REFERENCES}

Abel, J. (2006). Oracle E- Business Suite Security. Tata McGraw-Hill Education.

Aced-jordan.com. (2014, September 20). Success Stories. Retrieved from AcedJordan.com: http://www.acedjordan.com/success_stories

Aced-jordan.com. (2015, January 22). Aqaba Community and Economic Development (ACED II) Program. Retrieved from Aced-jordan.com: http://www.acedjordan.com/aced_program

Ammon News. (2010, June 20). US Ambassador Visits Aqaba, Inaugurates Third Annual English Summer Program, Tours USAID Projects. Retrieved from ammonnews.net:

http://en.ammonnews.net/article.aspx?arti cleNO=8542\#.WreFROhubIU

Anandi, R. (2009). Oracle 11i - The Complete Reference. Laxmi Publications.

Aureli, S., Ciambotti, M., Jóczik, A., \& Sasvari, P. (2015). Interpreting the Correlation Between the Capacity of Generating Added Value and the Use of Business Information Systems Through the Example of SMEs. Strengthening Information and Control Systems, 29-41.

Cokins, G. (2017). Enterprise Performance Management (EPM) and the Digital Revolution. Performacne Improvement, 56(4), 14-19.

Hull, R., Mendling, J., \& Tai, S. (2010). Business Process Management: 8th International Conference, BPM 2010,. Springer Science \& Business Media. 
James, D., Russell, S., \& Seibert, G. (2003). Oracle E-Bus. Suite Financials Hb. Tata McGraw-Hill Education.

Levi-Jakšić, M. (2012). Proceedings of the XIII International Symposium SymOrg 2012: Innovative Management and Business Performance. University of Belgrade.

Narayanamurthy, G., \& Gurumurthy, A. (2017). Revisiting the critical failure factors of ERP to explore their relationships - an ISM based approach. International Journal of Manufacturing Technology and Management, 31(6).

Noor Al Hussein Foundation. (2009). Aqaba Micro Business Incubator Commences. Retrieved from nooralhusseinfoundation.org: http://www.nooralhusseinfoundation.org/ index.php?pager $=$ end\&task=view\&type $=$ news\&pageid $=22$

Porwal, A. (2016). A Practical Guide to Implement Oracle E-Business Suite. Archway Publishing.
Radhakrishnan, R., \& Balasubramanian, S. (2008). BUSINESS PROCESS REENGINEERING: Text and Cases. PHI Learning Pvt. Ltd.

Siddiqui, M. A. (2010). Oracle E-Business Suite R12 Supply Chain Management. Packt Publishing Ltd.

Smiers, L., Deb, M., Koster, J., \& Palvankar, P. (2015). Oracle Case Management Solutions. CRC Press.

US-AID.gov. (2012, October 12). Jordan Aqaba Community and Economic Development. Retrieved from https://s3.amazonaws.com/usjkamp/prod _uploads/system/resources/attachments/0 00/000/482/original/Jordan-

Aqaba_Community_and_Economic_Dev elopment_2013.pdf?AWSAccessKeyId= AKIAIJL2X4Q3B25PE6DQ\&Expires $=1$ $521959113 \&$ Signature $=4 a 64$ yai0OQjJh3 METHDxebU0UqQ\%3D 